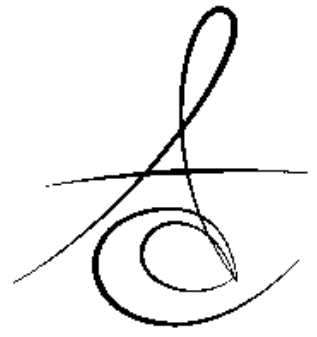

\title{
DİŞ MOBİLİTE TEDAVİSİNDE GÜÇLENDİRİLMİŞ POLİETİLEN FİBRİLER ŞERITT KULLANIMININ Dİş ETİ OLUĞU SIVIDAKİ HBD-1 MİKTARI ÜZERİNE ETKİSİ ${ }^{*}$
}

\section{EFFECTS OF USING REINFORCEMENT POLYETHYLENE FIBRILS STRIPS ON HBD-1 LEVELS IN MOBILITY TREATMENT}

Dr. Abdullah Seçkin ERTUĞRUL*

Dr. Ahmet Cemil TALMAÇ*
Dr. Ahu DİKİLİTAŞ*

Dr. Hacer ŞAHİN AYDINYURT*

\author{
Makale Kodu/Article code: 1304 \\ Makale Gönderilme tarihi: 10.09 .2013 \\ Kabul Tarihi: 28.01.2014
}

\section{ÖZET}

Amaç: Bu çalışmamın amacı, kronik periodontitis (KP) hastalarında periodontal problemler nedeniyle oluşmuş patolojik diş mobilitesini güçlendirilmiş polietilen fibriler şeritler ile tedavisinin diş eti oluğu sıvısındaki total human $\beta$ defensin-1 (hBD-1) miktarına etkisini değerlendirmektir.

Gereç ve Yöntem: Çalışmamıza periodontal problemler nedeniyle oluşmuş patolojik mobilitesi bulunan toplam 15 kronik periodontitis hastası dâhil edilmiştir. Başlangıçta ve 1 ay sonra çalışmaya katılan tüm bireylerin periodontal klinik indeksleri kaydedilmiştir. Çalışmaya katılan bireylerin faz 1 ve faz 2 periodontal tedavileri bitirildikten sonra güçlendirilmiş fibriller splint materyali ile periodontal splintleme işlemi yapılmıştır. Bireylerden diş eti oluğu sIVISı örnekleri splintleme işlemi öncesi ve splintleme işlemi sonrası 1. ayda alınmıştır. Diş eti oluğu sıvıSı örneklerinde human $\beta$ defensin-1 miktarı enzyme linked immuno sorbent yöntemi (ELISA) kullanılarak ölçülmüştür.

Bulgular: Çalışmaya katılan bireylerde splintleme öncesi ve sonrası klinik periodontal indekslerin değişimi karşılaştırıldığında gruplar arasında istatistiksel olarak anlamlı fark bulunmuştur. Splintleme öncesi alınan diş eti oluğu SIVISI örneklerinde total human $\beta$ defensin-1 miktarı, splintleme sonrası 1 . ayda anlamlı düzeyde azalma bulunmuştur.

Sonuç: Kronik periodontitis hastalarında periodontal tedaviye ek olarak patolojik diş mobilitesinin düzenlenmesi ile diş eti oluğunda human $\beta$ defensin-1 miktarı azalmaktadır. Bu durum güçlendirilmiş polietilen fibriler şerit kullanımının, patolojik mobilite nedeniyle periodontal dokularda oluşan yıkımı azaltabileceğini düşündürmektedir.

Anahtar Kelimeler: Kronik periodontitis, güçlendirilmiş polietilen fibriler şerit, human $\beta$ defensin-1

\section{ABSTRACT}

Aim: In the alveoler socket alloved by periodontal tissues tooth mobility is limited movement on the vertical and horizontal directions. Physiological mobility of the teeth, periodontal moderate force is applied, due to flexibility of the periodontium limited tooth movement. The aim of the present study is evaluate the effect of the Reinforcement-Polyethylene Fibrils Strips on gingival crevicular fluid (GCF) human $\beta$ defensin-1 levels in chronic periodontitis (CP) who have pathologic teeth mobility.

Material and Method: Totaly 15 patients who have a pathological mobility due to periodontal problem with chronic periodontitis were included in our study. The clinical periodontal parameters were recorded at the baseline and 1 month. After the phase 1 and phase 2 periodontal treatment periodontal splint treatment was performed with reınforcement polyethylene fibrils strips. Examples of gingival crevicular fluid are taken before and after the first month splint treatment. To measure human $\beta$ defensin-1 levels linked immuno sorbent method (ELISA) was used.

Results: Before and after the splint treatment clinical periodontal indexes found significantly difference between compared groups. Total human $\beta$ defensin- 1 levels in gingival crevicular fluid are found significantly decrased after the first month splint treatment.

Conclusion: In addition to periodontal treatment with a regulation of pathologic mobility human $\beta$ defensin-1 levels are decreased in chronic periodontitis patients. Use of reinforcement polyethylene fibrils strips may be beneficial to reduce the devastating effects of pathological mobility of periodontal tissues

Keywords: Chronic periodontitis, reinforcement poliethylene fibrils strips, human $\beta$ defensin- 1

*Yüzüncü Yı Üniversitesi, Diş Hekimliği Fakültesi, Periodontoloji Anabilim Dalı, Van, Türkiye

${ }^{\#}$ Bu çalışmanın bir kısmı 41. Türk Periodontoloji Birliği Kongresinde poster olarak sunulmuştur. 


\section{GİRIŞ}

Dişlerin vertikal ve horizontal haraketleri diş mobilitesi olarak adlandırılmaktadır. Dişleri destekleyen anatomik yapılar ve periodontal dokuların viskoelastik özellikleri diş mobilitesini etkileyen kritik faktörlerdir. Dişlere uygulanan hafif kuvvetler sonucu oluşan diş hareketleri sağlıklı periodonsiyum tarafından karşılanmaktadır. Bu durum fizyolojik mobilite olarak tanımlanmaktadır. ${ }^{1,2}$ Fizyolojik sınırların dışına çıkmış diş mobilitesi ise patolojik diş mobilitesi olarak adlandırılmaktadır ve periodonsiyumda zararlı etkilere neden olmaktadır. ${ }^{3}$ Yapılan klinik ve deneysel çalışmalarda fizyolojik sınırları aşmış diş mobilitesinin alveoler kemik kaybı, periodontal ligamentin niteliğinin ve niceliğinin değişmesi gibi birçok durum ile sonuçlandığı rapor edilmiştir.

Kemik yıkımının artması ile beraber periodontal dokularda fonksiyon kaybının ve generalize iskeletsel bozuklukların patolojik diş mobilitesine neden olduğu bilinmektedir. ${ }^{4}$ Patolojik mobilitenin en önemli nedeni kronik periodontitistir (KP). KP periodontal dokularda hasar ve alveoler kemikte yıkım ile karakterize bir hastalıktır. Diş yüzeyi temizliği ve oral hijyen alışkanlıklarının kazanılmasına ilave olarak okluzal düzenlemenin yapıldığı olgularda patolojik mobilitenin fizyolojik sınırlara gerilediği rapor edilmiştir. ${ }^{5}$

Mobilite dişin prognozunu tahmin etmede kullanılan çok önemli bir parametredir. Bu nedenden dolayı dişlerin prognozunu düzenleyip stabil hale getirmek için splint tedavisi önerilmektedir. ${ }^{6}$ Patolojik mobilitenin periodontal dokulardaki yıkıcı etkisini azaltmak için pinler ve kafes gridler periodontal splint amacıyla kullanılmaktadır. Bu materyallerin mekanik olarak bağlanabilme özelliği kullanım alanlarını daraltmaktadır. ${ }^{7}$ Geleneksel yöntemlerin başarısına rağmen kompozit içine gömülen güçlendirilmiş polietilen fibriler şerit popülarite kazanmıştır. Güçlendirilmiş polietilen fibriler şerit biyouyumlu, estetik bir materyaldir ve yüksek dayanıklılığa sahip polietilen fibrillerden oluşmaktadır. Diş konturlarına kolay adaptasyonu, oldukça güçlü yapısı, ışığı geçirme özelliği ve yapıştırma sürecinde kolay işlenmesi avantajları arasındadır. Kompozit rezin ile fibrilerin iyi adaptasyonundan dolayı uygulanan materyal yeterli dayanıklıı̆a sahip olmaktadır. ${ }^{8}$ Aynı zamanda polietilen lifler kompozit materyalinin dayanıkılığını, elastiklik modülünü ve bükülme direncini arttırmaktadır. Güçlendirilmiş polietilen fibriler şerit, kompozit rezin veya akril ile birlikte kullanılmaktadır ${ }^{7}$ Diğer fibrilerler ile karşılaştırıldığında matriks içinde görünmez halde bulunmaktadır. ${ }^{9}$

Periodontal dokulardaki enflamasyonun kontrol altına alınması ile fizyolojik sınırları aşmış diş mobilitesinin azaldığı bilinmektedir. ${ }^{10}$ Lindhe ve Nyman'ın yaptığı bir çalışmada ileri periodontal hastalığa sahip olan ve özenli şekilde plak kontrolü yapan 75 hasta 5 sene boyunca takip edilmiştir. Elde edilen sonuca göre mobil olan dişlerin yarıdan daha fazlasında alveolar kemikte herhangi bir değişim olmamasına rağmen mobilitelerinin azaldığı rapor edilmiştir. $^{10}$

Dental plakta bulunan bakteriler ve bakteriyel ürünler; monosit/makrofaj, lenfosit, fibroblast ve endotelial hücreler gibi hücrelerden pro-enflamatuar ve immuno-regülatör sitokinlerin sentezlenmesine neden olmaktadır. ${ }^{11}$ Periodontal hastalık oluşumu ve ilerlemesi immün sistem ve mikroorganizma arasındaki dengeye bağlıdır. ${ }^{12}$ Antimikrobiyal peptidler, bağışıklık sisteminin önemli bir üyesidir. ${ }^{13}$ Defensinler bir çok bakteri, mantar, protozoa ve bazı zarflı virüsleri yok etme yeteneğine sahip antimikrobiyal peptidlerdir. ${ }^{14}$ Human $\beta$ defensin-1 (hBD-1) ve human $\beta$ defensin-3 (hBD-3) mikroplara karşı periodontal dokuları korumakta çok önemli role sahiptir. ${ }^{15}$ hBD-1 ve human $\beta$ defensin-2 (hBD-2) temel olarak Gr (-) bakterilere etkili, hBD-3 ise $\mathrm{Gr}(+)$ ve $\mathrm{Gr}(-)$ bakterilerin her ikisine de etkilidir. ${ }^{16}$

Literatürde periodontal hastalıklar tedavi edildiğinde dişeti oluğu sıvısında (DOS) antimikrobiyal peptid seviyelerinin değişimini gösteren çalışmalar bulunmaktadır. ${ }^{11}$ Literatürde periodontal hastalık nedeniyle mobil hale gelen dişlerin periodontal tedaviye ek olarak güçlendirilmiş polietilen fibriler şerit ile splintlenmesinin DOS içerisindeki antimikrobiyal peptid seviyesinin değişimine etkisini sunan çalışma bulunmamaktadır. Çalışmamızın hipotezi periodontal doku kaybından dolayı oluşmuş mobil dişlerin periodontal splintleme yöntemi uygulanarak tedavi edilmesi sonucu daha fazla kemik kaybının önlenebileceği ve bu duruma bağlı olarak DOS'da hBD-1 seviyesinin azalacağıdır.

Bu çalışmanın amacl, KP hastalarında periodontal problem nedeniyle oluşmuş patolojik diş mobilitesinin güçlendirilmiş polietilen fiber şeritler ile teda- visinin DOS'daki hBD-1 miktarına etkisinin incelenmesidir. 


\section{GEREÇ VE YÖNTEM}

Araştırma grubuna, Yüzüncü Yıl Üniversitesi Diş Hekimliği Fakültesi Periodontloji kliniğine başvuran KP tanısı konulmuş toplam 15 birey dahil edildi. Araştırma için Yüzüncü Yıl Üniversitesi Tıp Fakültesi Girişimsel Olmayan Klinik Araştirmalar Etik Kurulu Başkanı̆̆ı'ndan onay alınmıştır (YYU-151112). Çalışmaya dahil edilen bireylere araştırmanın amacı ve içeriği anlatılmış ve Helsinki Bildirisi'ne göre gönüllü olarak çalışmaya katıldıklarına dahil bilgilendirilmiş onam formu imzalatılmıştır.

Çalışmaya dahil edilen hastalar sigara ve tütün ürünleri kullanmayan, sistemik rahatsızlığı bulunmayan, son 6 ay içinde periodontal tedavi görmemiş, son 6 ay içinde antibiyotik ve immün sistemi etkileyecek ilaç kullanmamış periodontal problemler nedeniyle oluşmuş miller tip 2 patolojik diş mobilitesi bulunan KP teşhisli kişilerden oluşmaktadır. ${ }^{17}$

Çalışmaya 1999'da yayımlanan Periodontal Hastalıkların Sınıflama Konsensüsü'nde belirtilen radyografik ve klinik kriterlere göre hastalar seçilmiştir. ${ }^{18} \mathrm{KP}$ hasta grubu, 20 ile 55 yaşları arasında 7 kadın ve 8 erkek olmak üzere toplam 15 hastadan oluşmaktadır. Hastalarda orta derecede ve ileri derecede kemik kaybı varlığı radyolojik film ile tespit edildi. KP tanılı bireylerden oluşan hasta grubunda; dişetinde enflamasyon, supragingival ve subgingival diştaşı ve plak formasyonu, radyolojik değerlendirmede vertikal ve horizontal kemik kaybı, tek köklü en az 4 dişin 6 bölgesinde sondalanan cep derinliği (SCD) $\geq 5 \mathrm{~mm}$ ve klinik ataşman seviyesi (KAS) $\geq 6 \mathrm{~mm}$ olan kişiler yer almaktadır.

Bireylerin klinik değerlendirilmesi periodontoloji kliniğinde kalibrasyon amaçlı tek çalışmacı tarafından yapılmıştır (AD). Klinik periodontal ölçümler splint tedavisi yapılan her dişin 6 bölgesinden (mesiyalbukkal, mid-bukkal, disto-bukkal, mesiyal-lingual, midlingual ve disto-lingual) yapılmıştır. Sondalamada kanama indeksi (SK), plak indeksi $(\mathrm{PI})^{19}$ gingival indeks $(\mathrm{GI})^{20}$ ve SCD'den oluşmaktadır. SCD manuel periodontal sond ile ölçülmüştür (Williams periodontal probe, Hu-Friedy, Chicago, IL, ABD). Cep derinliği; periodontal sond ile serbest dişeti kenarından cep tabanına olan mesafe, klinik ataşman seviyesi; minesement sınırından cep tabanına olan mesafe olarak belirlenmiştir.
Faz 1 ve faz 2 periodontal tedavi bitirildikten sonra güçlendirilmiş polietilen fibriler şerit materyali ile periodontal splintleme işlemi yapılmıştır. Hastalardan güçlendirilmiş polietilen fibriler şerit materyali ile periodontal splintleme öncesi ve güçlendirilmiş polietilen fibriler şerit materyali ile periodontal splintleme işlemi sonrası 1 . ayda DOS örnekleri toplanmıştır.

Her bireyin miller tip 2 mobilitesi ${ }^{17}$ bulunan SCD $\geq 5 \mathrm{~mm}$ olan iki faklı diş bölgesinden DOS örnek alındı. DOS örneklerinin her biri ayrı eppendorflara konuldu. DOS örnekleri toplanmadan önce steril küret ile dişlerin interproksimal yüzeylerindeki supragingival plak uzaklaştırılmış ve dişlerin yüzeyleri hava spreyi ile kurutulmuş ve rulo pamuklar ile tükürük izole edilmiştir. DOS kağıt filtre ile alınmıştır (PerioPaper, ProFlow, Amityville, NY). Kağıt filtreler hafif bir direnç hissedilene kadar mekanik bir travma oluşturmayacak şekilde dişeti cebine yerleştirilip $30 \mathrm{sn}$. bekletilmiştir. ${ }^{21}$ Eğer kağıt filtre kan ile kontamine olmuşsa çalışma dışı bırakılmıştır. Daha sonra toplanan kağıt filtreler, $500 \mu \mathrm{l}$ fosfatla tamponlanmış saline (PBS) içeren eppendorf türlerine konulmuş ve -70 derecede saklandı.

DOS'da hBD-1 miktarları enzime bağlı immunosorbent analizi (ELISA) kullanılarak ölçülmüştür. DOS'daki hBD-1 düzeylerinin belirlenmesinde ticari ELISA kiti (Alpha Diagnostic Inc., San Antonio, TX, USA) kullanılmıştır. Standartların hazırlanması amacıyla kit içerisindeki stok standart, üreticinin direktiflerine uygun olarak sulandırımıştır. Plak üzerindeki yerleri daha önceden belirlenmiş olan kuyucuklara hBD-1 için $100 \mu \mathrm{l}$ standart ve DOS örnekleri eklenmiştir. ELISA kitlerinde bulunan prosedürlere uygun şekilde işlemler yapılmıştır. Mikrotitrasyon plağı 450 nm'lik plak optik okuyucusunda (Microplate Reader Biotek, VT, USA) abzorbans ölçümleri yapılmıştır. Her bireyden alınan iki örneğin total hBD-1 miktarının ortalaması alınarak belirlenmişir.

Veriler, bilgisayar ortamında istatistik paket programı SPSS 16.0 kullanılarak değerlendirilmiştir. Klinik periodontal parametrelerin ve DOS verilerinin normal dağılım gösterip göstermedikleri KolmogorovSmirnov normalite testi kullanılarak tespit edilmiştir. Normal dağılım göstermeyen klinik periodontal parametreler ve hBD-1 düzeyleri splintleme öncesi ve sonrası değişimi Wilcoxon sıralı örneklem testi kullanılarak karşılaştırılmıştır. 


\section{BULGULAR}

Çalışmaya katılan bireylerin yaş ortalaması 35 olarak, yaş aralığı ise 20-55 olarak belirlenmiştir. Splintleme öncesi ve sonrası klinik periodontal indeksler (PI, GI, SCD, KAS ve SK) Tablo 1'de gösterilmektedir. Çalışmaya katılan bireylerde splintleme öncesi ve sonrası klinik periodontal indekslerinin (PI, GI, SCD, KAS ve SK) değişimi karşılaştığında splintleme sonrası periodontal indekslerin (PI, GI, SCD, KAS ve SK) splintleme öncesine göre istatistiksel olarak anlamlı düzeyde azaldığı belirlenmiştir $(P<0,05)$.

Splintleme öncesi ve sonrası total hBD-1 miktarları Şekil 1'de gösterilmektedir. Splintleme öncesi alınan dişeti oluğu sıvıSı örneklerinde total hBD1 miktarları, splintleme sonrası istatistiksel olarak anlamlı azaldığı belirlenmiştir $(p<0,05)$.

Tablo 1. Çalışamaya katılan bireylerden splint tedavisi uygulanan dişlerinin splintleme öncesi ve splintleme sonrası klinik periodontal indeksleri (Ortalama \pm Standart Sapma)

\begin{tabular}{|c|c|c|c|}
\hline $\begin{array}{c}\text { Klinik } \\
\text { Indeksler }\end{array}$ & $\begin{array}{c}\text { Splintleme } \\
\text { Öncesi }\end{array}$ & $\begin{array}{c}\text { Splintleme } \\
\text { Sonrası }\end{array}$ & $\boldsymbol{p}$ \\
\hline GI & $1,8067 \pm 0,4821$ & $0,8300 \pm 0,40347$ & $p<0,05$ \\
\hline PI & $1,7600 \pm 0,5991$ & $0,7267 \pm 0,2477$ & $p<0,05$ \\
\hline SCD (mm) & $4,2629 \pm 0,87019$ & $3,0243 \pm 0,62538$ & $p<0,05$ \\
\hline SK (\%) & $87,73 \pm 16,68$ & $41,13 \pm 15,25$ & $p<0,05$ \\
\hline KAS (mm) & $4,6933 \pm 1,29971$ & $3,0333 \pm 1,23501$ & $p<0,05$ \\
\hline
\end{tabular}

GI: Gingival indeks, PI: Plak indeksi, SCD: Sondalanan cep derinliği, SK: Sondalamada kanama indeksi, KAS; Klinik ataşman kaybı.

$p<0,05$ : gruplar istatistiksel olarak farklı

Şekil 1 Çalışmaya katılan bireylerin diş eti oluğu sıvısında total miktar hBD-1'in splintleme öncesi ve splintleme sonrası değişimi.

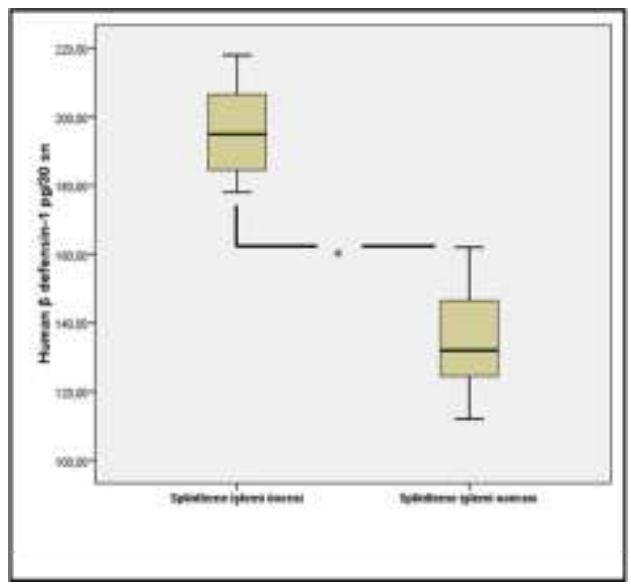

*Gruplar istatistiksel olarak birbirinden farklı $\mathrm{p}<0.05$

\section{TARTIŞMA}

$\mathrm{Bu}$ çalışma; KP'li bireylerde periodontal tedaviye ek olarak uygulanan güçlendirilmiş polietilen fibriler şerit ile dişlerin splintlenmesinin DOS'da hBD-1 miktarı üzerine etkisinin değerlendirildiği ilk çalışmadır. $\mathrm{Bu}$ çalışmada patolojik diş mobilitesinin periodontal tedaviye ek olarak güçlendirilmiş polietilen fibriler şerit ile tedavisi sonucu DOS'da hBD-1 miktarının azaldığı belirlenmiştir.

Ericsson ve Lindhe $^{10}$ tarafından yapılan deneysel çalışmaya göre alveoler kemik kaybı ve bağ dokusu ataşman kaybı diş mobilitesinin artmasına neden olmaktadır. Persson ve Svensson ${ }^{3}$ tarafından periodontal olarak sağıklı ve hastalıklı olan bireylerde diş mobilite değerleri ölçülmüş ve elde edilen sonuca göre periodontal hastalıklı kişilerde periodontal sağlıklı kişilere göre daha fazla diş mobilitesi olduğu gösterilmiştir. ${ }^{3}$ Yapılan çalışmada oluşan diş mobilitesi sadece alveoler kemik kaybı ile ilişkili değil aynı zamanda periodontal ligament ve yumuşak dokudaki değişimlerle de ilişsili olduğu belirlenmiştir.

Yapılan bir çalışmada oral epitelde hBD'ler ve sulkuler epiteldeki a-defensinlerin salınımı izlenmiş ve defensinlerin periodontal dokuların farklı bölgelerinde farklı rollere sahip olduğu bulunmuştur. ${ }^{22}$ Beta defensinlerin, temel olarak deri ve mukozadaki epitel hücreleri tarafından sentezlenmesinden dolayı bakteri enfeksiyonuna karşı ilk savunma hattında görev aldıkları düşünülmektedir. ${ }^{23}$ Değişik dokulardaki enflamasyon hBD-2 ve hBD-3 ekspresyonuna neden olabilirken, hBD-1 yapısal olarak oluşturulmaktadır. ${ }^{22}$ Bununla birlikte hBD-1'in aynı zamanda enflame dişeti dokusunda, hBD-2'nin ise sağlıklı durumlarda eksprese edildiğini gösteren bazı araştırmalar da mevcuttur. ${ }^{24}$ $\mathrm{Bu}$ çalışmada yapılan çalışmalara paralel olarak periodontal hastalığın tedavi edilmesine ilaveten mobilitenin azalması ile beraber hBD-1 düzeyinin azaldığı belirlenmiştir. Bu çalışmada sadece periodontal hastalığın tedavi edildiği ve mobilite tedavisi uygulanmayan kontrol grubu oluşturulmadığı için hBD1 düzeyindeki azalmaya mobilite tedavisinin ne derece etkisi olduğunu bilinmemektedir.

Mobilite diş prognozunu belirleyen önemli bir parametre olmasından dolayı tedavi edilmesi oldukça önem taşımaktadır. Bu çalışmada periodontal tedaviye ek olarak periodontal splint kullanımı ile beraber diş mobilitesinin değişimi değerlendirilmiştir. Periodontal 
tedavinin diş mobilitesi üzerine etkisi birçok çalışmacı tarafından araştırımıştır. Persson tarafından çeşitli periodontal tedavi işlemlerinin diş mobilitesi üzerindeki etkileri değerlendirilmiştir. Orta ve ileri düzeyde periodontitise sahip olan hastalara diş yüzeyi temizliği ve kök yüzeyi düzleştirmesi, gingivektomi ve flep operasyonları yapılmıştır. Bütün gruplarda diş mobilitesinde azalma görülmüştür. ${ }^{3}$ Fakat çalışmada radyolojik olarak kemik düzeyinde herhangi bir değişim gözlenmemiştir. ${ }^{3}$ Persson'a göre bu şekilde diş mobilitesindeki azalma enflamatuar lezyonun çözülmesi ile dişeti dokusunun tekrar organize olması sonucu oluşmaktadır. ${ }^{3}$

Dişlerin periodontal ve ortodontik nedenle yada travma sonrası splintlenmesi çok yaygın bir işlemdir. ${ }^{25}$ Yapılan çalışmalarda 1 . derece ve 2 . derece mobiliteye sahip dişlerin periodontal splint ile tedavi edimesi olumlu sonuçlar oluşturmuştur. ${ }^{26}$ Ayrıca diş mobilitesindeki azalma periodontal splint uygulanan test grubunda periodontal splint uygulanmayan kontrol grubuna göre daha fazla bulunmuştur. Aynı çalışmada aşırı mobil dişlerin periodontal tedavisinde periodontal tedaviye ek olarak periodontal splint uygulanması faydalı bulunmuştur. ${ }^{26}$ Yapılan bir çalışmada okluzal yüklemeden sonra liflerde açılma olmuş ve bu bölgeler akıcı kompozit ile kapatılmıştır. Bu çalışmada dişler ve kompozit rezinin rengi güçlendirilmiş polietilen fibriler şeritten etkilenmemiştir. ${ }^{27}$ Bearn rijit splintteki güçlen dirilmiş lifler fizyolojik hareketi sınırladığı ve düşük klinik başarı oranı göstermesi nedeniyle dezavantaja sahip olduğunu savunmuştur. ${ }^{27}$ Ramos ve ark. polimetil metakrilata gömülmüş olan güçlendirilmiş polietilen fibriler şeritin fiziksel özelliklerini laboratuar şartlarında test ettiklerinde kırılmaya direncinin daha yüksek olduğunu saptamışlardır. ${ }^{28}$ Güçlendirilmiş örgü polietilen fibriler şeritin akrilik rezinle birlikte, geçici restoratif materyal olarak uygulandığı bir çalışmada da, bu materyalin kırılmaya karşı daha dirençli olduğu rapor edilmiştir. Kırılma meydana geldiğinde de, fraktür hattının polietilen fibrile ulaşmadığı ve bozulmadan kaldığı saptanmıştır. ${ }^{29}$ Hornbrock ve Hasytings 24 olguda 12 aylık süre içerisinde klinik olarak güçlendirilmiş polietilen fibriler şerit ile birlikte uygulanan rezin restorasyonların kırılmaya direncinin daha yüksek olduğunu rapor etmişlerdir. ${ }^{30}$

Ön bölge tek diş eksikliklerinde alternatif olarak daha koruyucu ve ekonomik olan fibriler şerit ile güçlendirilmiş adeziv köprüler bir tedavi seçeneği olmaktadır. ${ }^{31}$ Fibriler şerit ile güçlendirilmiş kompozit inley köprüler tek diş kayıplarında kullanılabilmektedir.

Güçlendirilmiş polietilen fibriler şerit çocuk diş hekimliğinde kullanılan alternatif bir tedavi yöntemidir. ${ }^{32}$ Piovesan ve ark. tarafından yapılan çalışmaya göre polietilen fibriler şerit ile güçlendirilmiş kompozitten yapılan sabit protezler kaybedilen dişin yerine yapılan fonksiyonel ve estetik bir tedavi yöntemi olarak kabul edilmiştir. ${ }^{33}$ Ünlü ve Belli'ye göre fibriller ile güçlendirilmiş kompozitten yapılan sabit protezler 3 yıl boyunca fonksiyonel olabilmektedir. ${ }^{34}$ Diğer bir çalışmaya göre ise fibriller ile güçlendirilmiş kompozitten yapılan sabit protezlerin 4 yıllık takip sonucu \% 95 oranında fonksiyonel olarak kulanılabilme şansı olduğu belirlenmiştir. ${ }^{35}$ Yapılan çalısmaların sonuçlarına göre; yeni gelistirilen fibriler post sistemlerinin bağlayıcı ajanlarla ve kompozitlerle kombine edilmesi sonucunda yüksek estetiğe sahip restorasyonlar başarılı bir sekilde yapılabilmekte, diseti ve kök yüzeyi üzerinde meydana gelen metalik renklenmeler ortaya çıkmamaktadır. Bu sistemlerin kullanımı ile postun ve kökün kırılma olasılığının önemli ölçüde azaldığı ve daha estetik sonuçların elde edildigi kanıtlanmıştır. ${ }^{36}$ Travmatik yaralanmalar sonucu gevşemiş, kısmen ya da tamamen yerinden çıkmış dişler ve kök kırığı olan dişlerin sabitlenmesi için fibriler şerit splint materyali olarak kullanılmaktadır. ${ }^{37}$

Çalışmamızda mobil dişlerin tedavisinde periodontal tedaviyi takiben polietilen fibriler şerit kullanılmıştır. 1 ay sonra mobilite değerlerinde ve klinik parametrelerinde belirgin bir azalma görülmüştür. Radyolojik olarak herhangi bir değişim gözlenmemiştir.

Bu çalışmada hBD-1 seviyesi belirlenmesinde tükürük yerine DOS örnekleri kullanılmıştır. DOS serumdan kaynaklanan bir eksudadır ve dişeti oluğu boyunca bağ dokusundan enflame dokuya doğru akmaktadır. Örnekleme bölgesindeki lokal durum hakkında daha iyi bilgi verebileceği için DOS tercih edilmiştir. $^{38}$

Çalışma kiterlere göre sigara epitelin mikroorganizmalara karşı savunma gücünü azalttığı için sigara içen hastalar çalışma dışı bırakılmıştır. Ek olarak sigara enflamatuar hücrelerin migrasyonunu azaltarak, hBD-1 ve hBD-2 salınımını arttırmaktadır. Sigara içenlerde hBD-1 ve hBD-2 seviyesi sigara içmeyenlere göre yüksek bulunmuştur. ${ }^{39}$ Çalışmaya katılan bireylerin herhangi bir sistemik hastalığı bulunmamaktadır. Sistemik hastalıklar periodontal hastalığın şiddetini 
arttırarak, DOS'daki biyomarkerların seviyesini etkilemektedir. Ek olarak hamile olmayan ve en az 20 dişi olan hastalar bu çalışma için seçilmiştir. Bu çalışmaya dahil edilme kriterleri ölçüsünde 15 hasta sayısına ulaşılmıştır.

\section{SONUÇ}

KP hastalarında periodontal tedaviye ek olarak patolojik diş mobilitesinin fizyolojik sınırlara getirilmesi ile DOS'da hBD-1 miktarı azalmaktadır. Bu durum periodontal splintlemenin patolojik mobilite nedeniyle periodontal dokularda oluşan yıkımı azaltabileceği hipotezini desteklemektedir. Patolojik diş mobilitesinin periodontal dokular üzerindeki etkisinin anlaşılması için daha çok çalışmaya intiyaç duyulmaktadır.

\section{TEŞEKKÜR}

Çalışmamızı destekleyen 100. Yıl Üniversitesi Diş Hekimliği Fakültesi çalışanlarına ve desteklerini esirgemeyen doktora öğrencilerine teşekkür ederiz.

\section{KAYNAKLAR}

1. Mühlemann HR. Peirodontometry, a method for measuring tooth mobility. Oral Surg Oral Med Oral Pathol 1951;4:1220-33.

2. Mühlemann HR. Tooth mobility. The measuring method. Initial and secondary tooth mobiltiy. J Periodontol 1954;25:22-9.

3. Persson R, Svensson A. Assessment of tooth mobility using small loads. I. Technical devices and calculations of tooth mobility in periodontal health and disease. J Clin Periodontol 1980;7:259-75.

4. Wactawski-Wende J. Periodontal diseases and osteoporosis: association and mechanisms. Ann Periodontol 2001;6:197-208.

5. Ainamo J.Significance of epidemiologic research in the understanding of periodontal disease Scand J Dent Res 1992;100:39-46.

6. McGuire MK, Nunn ME. Prognosis versus actual outcome. III. The effectiveness of clinical parameters in accurately predicting tooth survival. J Periodontol 1996;67:666-74.

7. Aptekin NÖ, Belli S, Özkaya T. [The use of reinforcement polyethylene fibriler for periodontal splinting]. Cumhuriyet Üniversitesi Dişhekimliği Fakültesi Dergisi 1999;2:10-4.
8. Maden EA, Altun C. Use of Polyethylene Fibriler (Ribbond) in Pediatric Dentistry. Arch Clin Exp Surg 2012;1:110-5.

9. Vitale MC, Caprioglio C, Martignone A, Marchesi U, Botticelli AR. Combined technique with polyethylene fibrilers and composite resins in restoration of traumatized anterior teeth. Dent Traumatol 2004;20:172-7.

10. Lindhe J, Nyman S. The effect of plaque control and surgical pocket elimination on the establishment and maintenance of periodontal health. A longitudinal study of periodontal theraphy in cases of advanced disease. J Clin Periodontol 1975;2:67-79.

11. Dongari-Bagtzoglou AI, Ebersole JL. Gingival fibroblasts cytokine profiles in Actinobacillus actinomycetemcomitans-associated periodontitis. ] Periodontol 1996;67:871-8.

12. Brancatisano FL, Maisetta G, Barsotti F, Esin S, Miceli M, Gabriele M et al. Reduced human beta defensin 3 in individuals with periodontal disease. J Dent Res 2011;90:241-5.

13. Zasloff M. Antimicrobial peptides of multicellular organisms. Nature 2002;415:389-95.

14. Froy $O$. Regulation of mammalian defensin expression by Toll-like receptor-dependent and independent signalling pathways. Cell Microbiol 2005;7:1387-97.

15. Gursoy UK, Könönen E. Understanding the roles of gingival beta-defensins. J Oral Microbiol 2012;4. doi: 10.3402/jom.v4i0.15127.

16. Scott MG, Hancock RE. Cationic antimicrobial peptides and their multifunctional role in the immune system. Crit Rev Immunol 2000;20:40731.

17. Miller SC. Textbook of Periodontia. 3 st ed. Blakiston Co, Philadelphia: 1950. p.101.

18. Armitage GC. Development of a classification system for periodontal diseases and conditions. Ann Periodontol 1999;4:1-6.

19. Silness J, Loe H. Periodontal disease in pregnancy. II. Correlation between oral hygiene and periodontal condition. Acta Odontol Scand 1964;22:121-35

20. Löe $H$. The Gingival Index, the Plaque Index and the Retention Index Systems. J Periodontol 1967;38:610-6. 
21. Lamster IB, Hartley LJ, Oshrain RL, Gordon JM. Evaluation and modification of spectrophotometric procedures for analysis of lactate dehydrogenase, beta-glucuronidase and arylsulphatase in human gingival crevicular fluid collected with filter-paper strips. Arch Oral Biol 1985;30:235-42.

22. Dale BA, Kimball JR, Krisanaprakornkit S, Roberts F, Robinovitch M, O'Neal $R$ et al. Localized antimicrobial peptide expression in human gingiva. J Periodontal Res 2001;36:285-94.

23. Bals R.Epithelial antimicrobial peptides in host defense against infection. Respir Res 2000;1:14150 .

24. Lu Q, Samaranayake LP, Darveau RP, Jin L. Expression of human beta-defensin- 3 in gingival epithelia. J Periodontal Res 2005;40:474-81.

25. Hughes TE, Strassler HE. Minimizing excessive composite resin when fabricating fibriler-reinforced splints. J Am Dent Assoc 2000;131:977-9

26. Sekhar LC, Koganti VP, Shankar BR, Gopinath A. A comparative study of temporary splints: bonded polyethylene fibriler reinforcement ribbon and stainless steel wire + composite resin splint in the treatment of chronic periodontitis. J Contemp Dent Pract. 2011;12:343-9.

27. Bearn DR. Bonded orthodontic retainers: a review. Am J Orthod Dentofacial Orthop 1995;108:207-13.

28. Ramos V Jr, Runyan DA, Christensen LC. The effect of plasma treated polyethylene fibriler on the fracture strength of poly-methyl methacrylate. J Prosthet Dent 1996;76:94-6.

29. Samadzadeh A, Kugel G, Hurley E, Aboushala A. Fracture strenghts of provisional restorations reinforced with plasma-teated woven polyethylene fibriler. J Prosthet Dent 1997;78:447-50.

30. Hornbrook DS, Hastings $\mathrm{JH}$. Use of bondable reinforcement fibriler for post and core build-up in an endodontically treated tooth: maximizing strength and aesthetics. Pract Periodontics Aesthet Dent 1995;7:33-42.

31. Gönülol N, Kalyoncuoğlu E, Bulucu B. [Adhesive bridge applications with fibriler reinforced composites (report of three cases)]. The Journal of Dental Faculty of Atatürk University 2010;20:43-8.

32. Tuloglu N, Bayrak S, Tunc ES. Different clinical applications of bondable reinforcement ribbond in pediatric dentistry. Eur J Dent 2009;3:329-34.
33. Piovesan EM, Demarco FF, Piva E. Fibrilerreinforced fixed partial dentures: a preliminary retrospective clinical study. J Appl Oral Sci 2006;14:100-4.

34. Unlu N, Belli S. Three-year clinical evaluation of fibriler-reinforced composite fixed partial dentures using prefabricated pontics. J Adhes Dent 2006;8:183-8.

35. Freilich MA, Meiers JC, Duncan JP, Eckrote KA, Goldberg AJ. Clinical evaluation of fibrilerreinforced fixed bridges. J Am Dent Assoc 2002;133:1524-34.

36. Özdemir $E$, Agüloğlu S. [A crown restoratıon of fibriler reinforced composite which is

supported from the root canal]. Turkiye Klinikleri J Dental Sci 2006;12:123-6.

37. Sarıkaya I, Güler AU. [Prosthodontic Treatment of Crown Fractures with Using Fibriler Materials: Case Report]. Turkiye Klinikleri J Dental Sci 2009;15:234-40.

38. Golub LM, Kleinberg I. Gingival crevicular fluid: a new diagnostic aid in managing the periodontal patient. Oral Sci Rev 1976; :49-61.

39. Wolgin $M$, Liodakis $S$, Pries $A R$, Zakrzewicz $A$, Kielbassa AM. hBD-1 and hBD-2 expression in HaCaT keratinocytes stimulated with nicotine. Arch Oral Biol 2012;57:814-9.

\author{
Yazışma Adresi: \\ Ahu Dikilitaş \\ Yüzüncü Yıl Üniversitesi, \\ Diş Hekimliği Fakültesi, \\ Periodontoloji Anabilim Dalı, 65080, \\ Van, Türkiye \\ Tel: 04322251744 \\ Faks: 04322251747 \\ e-mail: ahuparlakdikilitas@hotmail.com
}

